EPOS, XIII (1997), págs. 209-218

\title{
MUJER Y CREACIÓN LITERARIA EN GUINEA ECUATORIAL
}

Mendogo Minsongui Dieudonne

Universidad de Yaounde I (Camerún)

¿Fuera de la temática? Quizás sí y quizás no. Muchos se preguntarán por qué un tema guineoecuatoriano aquí.

Por ser un país, el único país africano hispanofono, hemos preferido incluir esta temática aquí por varios motivos; insistiremos en dos:

Primero, la creación literaria de Guinea Ecuatorial es desconocida ${ }^{1}$ tanto en África como en Europa, y en el resto del mundo.

Segundo, dicha creación literaria es rica tanto en lo temático como en lo formal. Nuestro objetivo es llamar la atención de los estudiosos para investigar y dar a conocer la literatura ecuato-guineana, empresa en la que queremos contribuir con esta aportación.

La evolución narrativa ecuato-guineana, según observa Ciriaco Bokesa ${ }^{2}$, consta de tres momentos:

1 Vid. MBARE NGOM: «La literatura africana de expresión castellana: la creación literaria en Guinea ecuatorial». Hispania. 1993, 76, pp. 410-418.

2 CIRIACO BOKESA: «Ekomo, toda una novela», en Africa 2000. Malabo: Centro Cultural Hispano-Guineano, 1989, 10-11, pp. 95-97. 
1) La época colonial. Entonces la creación literaria es motivada por el proselitismo misionero, de que habla Augusto Olangua en Una Cruz en la selva, y por la biografía real o imaginaria de Cuando los Combes luchaban, de Leoncio Evita, o de Los que no se fueron, de José María Villa.

2) La época macista. En este periodo el silencio era la elocuencia de los bravos dentro del territorio nacional.

3) La etapa del 79. Desde el ángulo de la narrativa, hay como un repliegue hacia la conciencia del análisis a caballo entre la tradición y la importación cultural. A este tercer grupo pertenecen, por ejemplo, Ekomo (1985), de María Nsue Angüe y Las tinieblas de tu memoria negra (1987), de Donato Ndongo Bidyogo.

Entre los varios escritores a los que aluden Mbare Ngom y Ciriaco Bokesa en sus respectivos estudios, los cuales se complementan, destaca una sola escritora femenina: María Nsue Anguie.

María Pilar Nsue Angüe Osa, hija de José Nsue Angüe Osa y de Alfonsina Mangue, nace en Bidjabidjan en 1950, en una tribu Essasom. Casada en 1971 con José Mitogo, enviuda en 1974. Ahora es madre de cinco hijos. Consigue su bachiller selectivo en 1966 y se matricula en una universidad madrileña. Desde entonces vive en Madrid. Ha escrito muchas obras teatrales, ha realizado varias incursiones poéticas, pero sus escritos no son publicados. Su única novela publicada es Ekomo ${ }^{3}$.

Ekomo: ¿Novela femenista?

Ekomo es una obra original, una historia de amor entre dos jovenes, y refleja el pasado y el presente del pueblo. Un sinfín de anécdotas vividas por la protagonista hace de Ekomo una novela de lectura agradable.

La particularidad reside en los temas profundos que aborda la autora. Si la novela se inscribe en la tradición «fang», podemos afirmar que, entre tomos temas sobresalientes, el de la mujer «fang» ocupa un gran espacio. José Antonio López Hidalgo afirma al respecto:

María Nsue, en cambio, hace hincapié en la situación -marginal- de la mujer, dentro de las estructuras familiares africanas, $y$, sus secuelas de angustia que deriva a menudo en soledad existencial...

Mbare Ngom, abundando en el mismo sentido, dice:

${ }^{3}$ Maria Nsue Angue: Ekomo. Madrid: UNED, 1985.

4 JOSÉ ANTONIO LOPEZ HidALGO: «La novela en Guinea ecuatorial», en África 2000. Malabo: Centro Cultural Hispano-Guineano, 1993, n. $^{\circ} 20$, pp. $42-44$. 
En sus diez capítulos de amena lectura, la obra de María Nsue recoge las vicisitudes de la vida de Nnanga, mujer fiel en la búsqueda de su identidad como ser humano y como mujer y, por ende, de su libertad en un universo que le impone muchas restricciones. Al enfocar la historia desde la perspectiva de Ekomo, un personaje masculino, la autora puede, dentro de las normas de ese mundo, pasear una mirada crítica y legítima sobre su estructura patriarcal. La figura de Nnanga, la verdadera protagonista de la novela, es la de un personaje tiroteada entre un pasado cargado de tradición y un futuro lleno de promesas.

A este nivel, no sólo plantea el conflicto entre tradición y modernidad en una sociedad en proceso de cambio, sino que también trata de la condición de la mujer guineana en un universo tradicional patriarcal y patrilocal como el bantús.

La novela aborda, pues, la problemática de la mujer africana (fang) de Guinea ecuatorial y, entre los muchos problemas sublevados, podemos mencionar los siguientes:

- La mujer «fang» entre la tradición y la modernidad.

- El matrimonio y sus problemas.

- El adulterio.

- La dote.

- La poligamia.

Como podemos notar, María Nsue Anguie, aunque de momento es la única mujer escritora conocida de Guinea ecuatorial, su escritura es rica tanto temática como formalmente.

La temática de la mujer es de gran importancia en esta obra. Pensamos que en próximos estudios, podremos abordar dicha temática.

\section{LA MUJER FANG ENTRE LA TRADICIÓN Y LA MODERNIDAD}

Como hemos señalado más arriba, estamos en una sociedad patriarcal donde la mujer desempeña un papel secundario. La mujer es marginada, no tiene nada que decir frente al hombre, que lo decide todo. El texto de la novela, a través de Nnanga Abaha, afirma al respecto:

s Mbare Ngom: art. cit., p. 417. 
La vida de una mujer está siempre expuesta a las decisiones del abaha desde que nace hasta que muere (p. 188).

Por ese motivo, cuando hablan los hombres en el «abaha», se callan las mujeres.

El tema de la mujer es uno de los temas que abre el conflicto entre tradición y modernidad; de ahí la crisis entre dos generaciones. Dicha crisis se desprende de los casamientos de Samuel y Nnanga Abaha. Asistimos en el relato a dos casamientos, ambos por raptos (pp. 1232-150). A partir de estos raptos, surge el problema del enfrentamiento entre la vieja y la joven generaciones: los padres, dictadores, y los jóvenes, ejecutores; en definitiva, opresor frente a oprimido. La vieja generación quiere transmitir a sus descendientes las costumbres, las tradiciones del pueblo. Por eso, el padre de Samuel, que actúa según la tradición, elige compañeros a sus hijos. Elige una mujer de buena educación a su hijo Samuel, la hija del pastor. Nnanga también tiene que casarse con un mozo de buena familia: el padre la conserva para el hijo del catequista Lucas. Pero ocurre lo contrario. Samuel decide raptar a Bitomo, a quien quiere. El narrador precisa:

La había raptado para evitar tener que casarse con la hija del pastor con la que estaba prometido (p. 132).

Nnanga, a sus catorce años, se burla de su padre y de todo el pueblo el día de su boda tradicional con Lucas. Tras todas las ceremonias de boda, acepta ser raptada por Ekomo:

No hables... Soy yo, vengo a buscarte $[\ldots]$ ¿Quieres venirte conmigo, verdad? Volví a decir que sí con la cabeza (pp. 147-148).

Ni Samuel ni Nnanga nada dicen a su padre por miedo, como se lo recuerda Nnanga para convercerse de que su hermano ha actuado bien:

Nadie le hubiera hecho caso, Samuel no se habría casado nunca con la muchacha que quería si se lo hubiese dicho a mis padres porque estos nunca escuchaban, sólo ordenaban y se hacía lo ordenado (p. 132).

La rebelión de la mujer participa, así pues, de la caída de los valores culturales tradicionales. Los jovenes quieren opinar acerca de sus casamientos. La ilustración de tal aseveración la hallamos en el diálogo entre Bitomo y su camarada Nnanga, cuando la primera dice a la segunda: 
Mi querida hermana, si otras muchachas se casan con los hombres que quieren, ¿puedes decirme por qué tú no? (p. 138).

Esta situación se debe a que en la tradición «fang» los padres son quienes deciden; la mujer no dice nada.

Hay un caso de un matrimonio obligado en la novela, el caso de Adjaba, hermana de la narradora. Se ha casado con un hombre a quien no quería:

... recuerdo las muchas noches que pasaba llorando a solas, cuando pensaban que estaba dormida. Ella tampoco quería casarse con el suyo (p. 140).

Otra rebelión de la mujer se manifiesta cuando Nnanga Abaha toca el cadáver de su difunto marido. Razón por la cual una voz interior le dice:

Faltaste al tabú..., faltaste al tabú... Tocaste el cadáver de tu marido muerto ¡Morirás! (p. 181).

El pastor, como cristiano, interviene y defiende a Nnanga Abaha. Le pide que se levante. Lo hace después de vacilar bastante. Este acontecimiento simboliza la cumbre del conflicto entre las dos generaciones.

Volveremos a este aspecto a continuación al hablar de la viudez.

Para concluir este apartado, diremos que la mujer fang es esencialmente tradicionalista tal como es presentada en Ekomo. Si la división del trabajo queda notable, notaremos que de todo este trabajo se encarga la mujer. Cada una trabaja en su finca (p. 92). A lo largo del camino hacia la misma, o en el río, o de regreso al pueblo, comadrean las mujeres entre ellas. Se burlan, por ejemplo, de Avoro porque va a casarse con «un viejo con un pie en la tumba y otro en ese mundo» (p. 92). Comentan sobre la danza sagrada (p. 29). Además, la mujer tiene que cocinar para toda la familia; Madre por ejemplo prepara la comida colectiva (p. 71).

En Ekomo de María Nsue Angüe, ninguna mujer es instruida, y esta situación pone de relieve la insistencia de la autora en las tradiciones de su pueblo, y sobre todo la situación marginal de la mujer en un universo patriarcal como el «fang».

Conviene subrayar, sin embargo, que, aunque la mujer es analfabeta, se nota su afición al arte, sobre todo a la danza. Es una costumbre en la tradición «fang». Las mujeres suelen ser bailadoras. En la novela, el ejemplo de la nueva danza a la que se aficionan Nnanga Sara y sus amigas ilustra nuestro propósito. Ella se vuelve artista más tarde, una bailarina famosa y atractiva (p. 74). Antes de casarse, dará muchos giros artísticos a través de otros pueblos. 
2. El pROBLEma de la VIUdeZ

El tema va relacionado con el primero. Diremos que es una continuación del mismo.

Sara está sufriendo los castigos de viuda, duras pruebas después de la muerte de su esposo Ekomo. Está echada entre las cenizas y no puede moverse porque, al hacerlo, viola un tabú, como tocar el cadáver de su marido. Además de estar echada entre las cenizas, recibe palazos de vez en cuando:

Estoy echada entre las cenizas. ¡Es natural! ¡Soy una viuda, pero me pican las hormigas y no puedo moverme porque es tabú! Con los palos sobre mi cuerpo. ¡Es natural! Soy viuda y todos tienen derecho a flagelarme (p. 184).

Tiene que permanecer entre las cenizas, esperando su muerte inminente, ya que no debe comer mientras tiene hambre:

Tengo hambre, sed y frío. Es curioso... ;Como grita la gente! y yo aquí, entre las cenizas. Tendré que estar aquí hasta que también me alcance la muerte (p. 186).

Dado su estado físico de enfermedad, un problema se plantea en el pueblo que se ve preocupado, problema que le es imposible resolver.

Según las torturadoras, y de acuerdo con las normas del rito, la viuda no se levanta antes de que pasen las vigilias por el difunto. Si ocurre el caso, se volvería loca según la tradición. Philippe Laburthe-Tora ${ }^{6}$ subraya también este aspecto en su estudio.

El padre quiere y propone que se levante su hija, porque se exigen las normas para una mujer que esté bien de salud. Y en eso llega el Pastor de la iglesia. Está sorprendido al ver que el pueblo, al insistir en el respeto de las costumbres, quiere matar a Sara. Decide violar la tradición, lo que llaman tabú, levantando a Sara en el nombre de Jesucristo. Le ordena levantarse (p. 191). Tras unas vacilaciones, Sara se arrastra hacia el Pastor, quien le ayuda a levantarse ante todo el pueblo.

La acción del Pastor simboliza la dominación de la iglesia sobre la población y sus costumbres. Conviene recordar aquí que la cruz y la espada han sido dos emblemas que se fueron a la conquista y dominación de las colonias. $Y$

- Phil IPPE LABurthe-TOBRA: Initiations et societés secrétes au Cameroun (Les mystères de la nuit). Paris: Khartala, 1985, p. 205. 
con Ekomo, estamos en el período colonial en Guinea ecuatorial. Aquí, la cruz domina el pueblo y lo obliga a abandonar su tradición. Escuchemos lo que dice el padre de Sara a este respecto:

... no podemos volver atrás y sentarla otra vez en el suelo (p. 193).

Sin embargo, todos piensan que ella va a morir, ya que ha cometido una falta, ha violado un tabú:

Todos me llaman maldita y esperan que de un momento a otro me alcance la muerte terrible (p. 192).

Los malos tratos a los viudos es algo idóneo a la tradición fang. A continuación tenemos el testimonio de Juan Bautista Osubita:

El viudo o la viuda deberán someterse al acatamiento de las severas penas e insultos que les imponen para purgar su delito. Pero es aquí donde reside toda la ambigiledad de funciones de la víctima designada, pues la aceptación de su triste situación apunta a la solución del grupo, pero se revela asimismo como una catarsis individual. Para este último fin, se hará hincapié en la prohibición de hablar y en la restricción alimenticia...?

\section{MUJER, MATRIMONIO E HIJOS}

En la tradición fang, la mujer debe dar a luz. Su papel consiste en ser madre de familia. En Ekomo, algunos casos llaman la atencion al respecto.

La mujer de Oyono, por no tener hijos con su marido, permite a éste casarse con una moza que podrá dar a luz. Dice lo siguiente:

... nos negaron la descendencia, privando a mi viente parir hijos, motivo por el que viendo la tristeza de él, y comprendiendo que nuestra casa no habria de cerrarse una ver muertos los dos, aconsejele coger el dinero ahora y buscarse con el otra moza que pudiera parir hijos... (p. 95).

7 Junn Bautista OSUBrTa: «Semiología de la muerte fang», en África 2000. Malabo: Centro Cultural Hispano-Guineano, 1993, n. ${ }^{\circ}$ 20, pp. 7-13. 
La mujer de Ekomo está atormentada por no tener hijos después de dos años. Expresa aquí un deseo ardiente de tener una criatura:

Y cuando, instintivamente alarga el brazo y siento junto a mí su cuerpo caliente, mi alma se llena de congoja porque, en principio, me doy cuenta de lo importante que sería, para los dos, ser padres. Brotan de mis ojos lágrimas [...] deseando con ardor que Dios, el gran Dios, bendiga nuestra unión [...], trayéndonos una criatura a quien algún día poder cantar aquella misma nana (pp. 48-49).

I:xlc deseo le lleva a hacer la prueba de Ondo el Divino, para ver si es estéril (p. 109). Después de la muerte de su marido, nadie quiere que se quede una mujer estéril. Y, según la tradición, su familia debe devolver la dote para dársela a otro que logre casarse con una mujer que pueda dar a luz (p. 188).

La importancia de los hijos en esta sociedad se debe a que constituyen mano de obra. Nnanga Sara pone de relieve dicho aspecto:

... y tener hijos que han de servir después en la casa... (p. 188).

Ucuparse de su hogar, trabajar en el campo y procrear son las principales ocupaciones de una mujer guineoecuatoriana tradicionalista.

\section{El adULTERIO, LA DOTE Y LA POligamia}

En Ekomo, aparecen dos casos de adulterio. El primero se refiere a Nchama, calificada de "pícara zalamera». A causa de ella, el anciano convoca una reunión en el «abaha», tribunal del pueblo:

«En el abaha, los hombres discuten. Todos hablan de Nchama, la pícara zalamera que ayer en el bosque cometio adulterio...» (p. 17).

Otro caso es el de la tercera mujer del polígamo Oyono. Dice la narradora hablando de ella:

Yo recordé que era además de Nchama, una de las mujeres más adúlteras del pueblo (p. 97).

Lo que llama nuestra atención es que el adulterio está prohibido en la tradición fang: el que lo comete es sancionado como Nchama y su hombre.

Y la sentencia es pronunciada por el viejo que preside el consejo de ancianos en el «abaha». 
¿Queda esta sentencia! -grita el viejo-. Para la adúltera, cincuenta palos en el trasero. $Y$ continúa diciendo mientras carraspea- para el adúltero, dos cabras, treinta mil bipkwuele y ciento cincuenta palos. Porque la mujer es como un niño. No tiene conciencia de fidelidad. Y su culpa, por lo tanto, es menor. Todos recordaréis que se dijo en la antiguiedad: «No busques a la mujer de tu hermano». Y con eso se quiso decir que el hombre no debe incordiar a la mujer ajena, porque ella es como las hojas de los árboles: ama según la dirección en la que viene el viento. Pero el hombre es consciente de su propio mal en este sentido (p. 18).

En Ekomo, se menosprecia a las prostitutas. Son mujeres de mala vida que embrujan a los hombres en la ciudad. Tal es el caso de la famosa ramera que intenta curarse de la maldición en casa de Ondo el Divino:

... Era una famosa ramera de la ciudad sobre quien había caído la maldición, porque había tenido relaciones ilícitas con un hombre muy respetable de la ciudad casado canónicamente, le había embrujado de tal modo que el hombre había abandonado a su mujer e hijos para ir a vivir con ella, y la mujer de éste había acudido al obispo del lugar haciéndole ver todo el daño que ésta causaba a la familia. Entonces, el Obispo después de llamarla le pegó con el cinto en la cara que es sagrado y la maldijo. El hombre, sin saber como dejo de quererla, se volvió con los suyos, y desde entonces, que van varias lluvias, la oscuridad caý sobre la mujer y nadie más volvió a mirar su rostro como rostro de persona (p. 107).

Hay otros problemas que se plantean como el de la dote. En nuestra obra, tan sólo se alude a él. Vemos que la mujer de Ekomo está atormentada por no tener hijos. Después de la muerte de su marido, nadie quiere que se quede estéril (p. 109). Y, según la tradición, su familia debe devolver la dote para dársela a otro que pueda casarse con una mujer que les traiga hijos (p. 188).

En cuanto al problema de la poligamia, tenemos el caso de Oyono. Tiene cuatro mujeres, $y$, al querer bautizarse, tiene que repudiar a tres según las normas del catolicismo. De aquí, el conflicto que llevan al «abaha». Se nota en la novela cierta justificación de la poligamia a través de la segunda mujer de Oyono:

Escogí a Oyono para esposo sin saber que lo que pretendía de mí era mi matriz fértil para la felicidad de su esposa, a quien en un principio acepté al llegar al pueblo (p. 96). 
En efecto, Oyono y sus mujeres están en el «abaha» bajo sus iniciativas, porque ninguna quiere ser dejada:

Pues las mujeres de Oyono piensan llevar a su marido al Consejo de Ancianos porque ninguna quiere ser dejada y todas quieren que se bautice con cada cual (p. 92).

Mujer y creación literaria en Guinea ecuatorial. El tema es interesante y tiene que llamar la atención de los estudiosos. María Nsue Anguie, en su pluma revolucionaria, pone de relieve en su escritura feminista la problemática de la mujer «fang» tradicionalista de Guinea ecuatorial. Dichos problemas son los que hemos venido señalando a lo largo de este estudio. Nuestra investigación no está cerrada. Pensamos que, andando el tiempo, la iremos desarrollando.

Después de todo lo dicho, podemos opinar que María Nsue Angüe es una escritora femenista; defiende la tradición, pero, lucha también por la emancipación de la mujer. Dicha postura se nota cuando Nnanga Abaha «falta al tabú» al tocar el cadáver de su difunto marido, y sobre todo cuando el Pastor le pide levantarse del suelo, poniendo así fin a las durísimas pruebas de viudez. 